\title{
Experience in receiving and practicing self-care as a person affected by leprosy
}

\author{
Sopna Mannan Choudhury ${ }^{\mathrm{a}}$ \\ ${ }^{a}$ Institute of Applied Health Research, College of Medical and Dental \\ Sciences, University of Birmingham, Edgbaston, Birmingham, B15 2TT, UK \\ e-mail: s.m.choudhury.1@bham.ac.uk
}

ORCID: https://orcid.org/0000-0001-5017-6977

Submitted 11 November 2021; Accepted 16 November 2021

\section{Introduction}

For people affected by leprosy, self-care is one of the strategies used to prevent secondary disabilities and manage the risk of ulcers. Self-care in leprosy was described and developed into a training program by Jean Watson during the 1970's and 1980's. ${ }^{1}$ Self-care interventions for people affected by leprosy are about educating them on skin and wound care activities, and supporting them to manage their own condition, rather than relying on health care services. It often incorporates a process of inspecting, soaking, scraping and oiling skin, and dressing wounds. The aim is to keep skin and wounds clean, callous free and well moisturised, to prevent or manage the formation of ulcers.

Self-care also incorporates simple risk reduction measures, such as reducing pressure on the feet by walking less and resting wherever possible; using pressure-relieving devices such as crutches or suitable footwear; using adapted tools to avoid mechanical trauma and pressure injuries; and using protective cloths to prevent burn injuries.

Here we present four accounts from people diagnosed with leprosy about their experiences and how they have learnt to manage and live with their condition. The first two patients have visible deformities and speak about coming to terms with the consequences of leprosy. The second two accounts speak of their diagnosis and, whilst they do not have overt physical deformities, the preventative measures they take to avoid any issues arising.

ACCOUNT 1: KASHI NATH ARYAL, 61 YEARS OLD FROM NEPAL

I have been working in Anandaban Hospital since 1991 as an ulcer dresser. I have firsthand experience of leprosy; I was diagnosed when I was a young boy and I live with the consequences of the condition. My hands and feet are deformed due to leprosy and I have been admitted to Anandaban hospital 24 times to treat complications-mainly feet ulcers. 
I have learned about the importance of self-care during multiple admissions to Anandaban Hospital. Self-care is an important part of my daily routine and I need to take special care of my eyes, hands and feet. Although self-care can be challenging, I am motivated to maintain self-care through being an example to others and teaching.

There are three main aspects to my self-care routine. For my eyes, I wear sunglasses outside to prevent any damage caused by the sun. For my hands, I apply mustard oil twice a day before and after I start work, and I do hand exercises every evening to keep my fingers supple and straight.

Looking after my feet is a very important part of my self-care routine. When I come home from work, I inspect my feet carefully for any blisters or scratches. I wash my feet every day and put mustard oil on them. Once a fortnight I soak my feet for about 20-30 minutes. I scrape any hard callouses on my feet and I massage my feet with mustard oil. To protect my feet, I have arch supports in my shoes and I bandage my feet very carefully each day to prevent any pressure points emerging as I go about my daily tasks.

I have gained a lot of my knowledge about self-care in leprosy through my work as an ulcer dresser in Anandaban hospital. The physio team have taught me so much. A key part of training about self-care is explaining the reasons why it's important to do it regularly and thoroughly. Thanks to the support I have received, I've not had any ulcers since 1991. I'm grateful to the physio team and all the care I receive through the Anandaban Hospital and the Leprosy Mission, Nepal.

\section{ACCOUNT 2: ANONYMOUS MALE, INDIA}

I was diagnosed with leprosy 22 years ago when I was an adolescent. It started when I experienced difficulty in walking. When I visited the doctors, I was diagnosed with foot drop due to leprosy and I realized that I had developed anaesthesia of my right sole. I was in college at that time, and it was a devastating diagnosis for me. I did not know the consequences of leprosy at the time but I had a sense it was something bad and it upset me a lot. My father was also upset hearing the diagnosis, but his support for me never wavered.

I was given foot drop spring shoes to help me walk and you can imagine how much stigma I faced, not only in the college but also within myself! The shoes were a source of ridicule among my friends as they were so visible, and I was embarrassed all the time because of them. However, it was beneficial as it helped me walk properly and overcome my foot drop. Anyway, after I had corrective surgery, I got rid of those shoes. I also had claw toes, which were corrected by arthrodesis.

I was taught self-care at that point and was told that if done properly and regularly it would save my foot. I was taught to soak my feet, scrape, and oil them daily and do exercises. I was also told that self-care was something you need to do for the rest of your life. It seemed such a chore to me and was embarrassing. When I was young, and I lived in a village, finding a private space to do this was a challenge. In the village settings, there is no privacy, and people always ask about your private life. Imagine sitting in the open with my feet soaking in a tub of water! I used to feel embarrassed to practice self-care even at home, but my parents were very supportive.

I was angry that something like this could be thrust on me for the rest of my life. As days went by, there were many thoughts that came into my mind but the most important one for me was to get a solution for all of this once and for all. I later developed an ulcer on the base of the first toe and was told that a little bit of rest, along with self-care would heal it. I asked the 
doctors' multiple times to amputate my toe, thinking that would be the solution to all of my problems, but I was told that it could lead to worse consequences.

After I had the foot drop surgery, Micro Cellular Rubber (MCR) sandals were enough. I tried many other so-called 'soft market' shoes but none of them were as good as MCR. Despite spending a lot of money on market shoes, I now use only MCR and use them as insoles inside my sports shoes. I regularly change my insoles so that my feet are protected. Self-care has really made a difference to my feet and I'm now in an established routine. Even though I don't do it daily, I do self-care frequently enough so that my feet are soft and supple and there is no risk of ulcers. This involves soaking my feet two to four times a week, doing daily exercises and scraping out/cutting callouses when needed (sometimes this involves surgery). After soaking my feet, I usually apply mustard oil, which helps to keep my skin supple and smooth for a longer period.

There were a lot of challenges to practicing self-care. Initially, I used to neglect practicing self-care because I was angry and frustrated. I was young and outgoing at that time and would consider it a waste of time! Whenever I would find time, I would soak my feet and would see the difference. I slowly learnt the value of self-care through experience. Whenever I used to go for a medical consultation, self-care for my feet was reinforced. I would be irritated by the repetition but now I know that my doctors and nurses were my well-wishers and wanted the best for me.

I am now married with two children and living in a city and not the village. Taking time out for routine self-care is a great challenge for me, even now. Earlier it was my embarrassment and unwillingness but now I am just too busy. Apart from my work as a manager, I have household chores to do. There just aren't enough hours in the day. I am fortunate to have a supportive spouse who reminds me about my routine self-care and tells me off if I put it off or forget. As the children are growing up, they understand the significance of the ritual of self-care in their father's life and are quick to remind me when I neglect my routine.

ACCOUNT 3: AMAR BAHADUR TIMALSINA, NEPAL

I'm not afraid to say that I am a person with Hansen's disease (Leprosy). I was born into a poor family in a remote village in Nepal, where there were no roads or electricity. Delving into my deepest memories, I can picture myself herding cattle, carrying fodder for them, cleaning the cowsheds, compromising on food and clothes but still moving on. Poverty was very real to us! Nowadays, hardly anything has changed.

When I turned ten, my whole life was turned upside down! I was struck with an unknown disease. There were visible signs on my body and my left foot became numb with innumerable cracks visible on the sole. My health was getting worse as each day passed. A visit to the hospital was out of the realms of possibility, so I was taken to a local witch doctor. The outcome: nothing!

But I was very worried about my health. Although I was pain-free, I took great care of my foot-I always ensured that my slipper was perfectly fitted. I also cleansed the cracks time and again, ensuring that no soil, dust or other particles got into the cracks. I was well-aware of the danger of fire and was always very careful not to get burnt while huddling near the fire in the cold. These efforts greatly helped me live with the disease. Luckily, I did not have any visible deformity because of the attention I paid to self-care.

A relative somehow convinced my parents to take me to the doctor and we sought medical care. We wandered from place to place in Kavre, and finally into Kathmandu. Wherever we went, we received the same news: undiagnosed ailment. 
It was only when we visited the Tribhuvan University Teaching Hospital, a senior physician suspected leprosy and I was referred to Anandaban Leprosy Hospital. There, I was diagnosed with leprosy. My parents left me at the hospital for further treatment, and went home. I stayed there for about three months. During the ward rounds, the clinicians would give us advice. During my stay at the hospital, I met many people just like me. The support we received from each other was so valuable. We would console each other without any hesitation and share experiences. This largely helped us win our individual battles against leprosy. My health condition did not deteriorate because of early diagnosis and timely treatment. Importantly, we learnt so much about self-care from hospital staff, which we strictly followed. We were taught the importance of daily self-care and how we need to take special care of our eyes, hands and feet. We were taught about soaking our feet regularly for 20-30 minutes, scraping and also oiling.

In terms of my own care, I was not afraid about having leprosy since I had no visible deformity and no severe ulcers on my body. People with ulcers are prone to stigma, which means they are more likely to cover them up or reluctant to administer self-care in the presence of others. As a result, the ulcers get worse. In my case, I had no wounds and my self-care was much easier. Even so, I keep up a regular routine of checking my limbs, ensuring I have the right footwear and am not developing any cracks or ulcers.

Every now and then, I visit Anandaban Hospital for follow-up appointments. I have been admitted to hospital several times due to Erythema Nodosum Leprosum (ENL) reactionsthe pain is intolerable. ENL reactions are more dangerous and more painful than the ulcers I feel! At one point, I had blisters all over my body like the ones you can get after getting burnt. Regular medication and check-ups were carried out by clinicians while I was also taught how to clean the small wounds caused by those blisters on my body. I was always meticulous about my personal hygiene - I took daily baths and changed my dressings daily. I can't describe the pain of bathing the blisters but I understood the importance of strict adherence to hygiene!

Whilst there is no substitute for early diagnosis and medication, self-care is so very important to minimize the impact of leprosy and plays a vital role in my day-to-day life living with leprosy.

ACCOUNT 4: JAYASHREE KUNJU, INDIA

Although I was diagnosed with leprosy 38 years ago, I still live with the visible remnants of the disease. The little finger and ring finger on my right hand are clawed and I also have muscle wastage. I have learnt to live with my hand and it does not stop me from everyday activities: I drive a car, I cook, and I work on my computer. As I have loss of sensation on parts of my right hand, I do need to be careful. I have learnt to work around hot objects in the kitchen without hurting myself: I use a mitten to pick up hot objects and also work with my good left hand. My condition has not led to any ulceration, dry skin, etc. which many people with leprosy could end up having to live with. I guess, life might have been unbearable if I would have lived with such conditions. Yet, I meet and talk to people with leprosy who have to deal with ulcers, dropped foot, dropped wrist, visible weakness and muscle wastage. Many times, people have an ulcerated foot that takes forever to heal due to the pressure exerted to take normal steps. People with such conditions find it hard carrying out even simple, everyday tasks but keep going because they need to.

I was one of the lucky ones. I was diagnosed early and received effective care. Others aren't so fortunate. I've been volunteering my time working with various agencies that support people with leprosy. Not only do these agencies raise awareness of leprosy amongst the 
general community, but they also help educate people affected by leprosy on self-care and the consequences of lack of self-care. I have seen, first-hand, how attention to self-care can have a massive impact on someone's life. Over the past six years, I have seen how leprosy in a young lady deteriorated drastically. At first, both her hands and feet were affected and then she ended up with ulcers on all her limbs. For a few years she had a series of corrective surgeries. However, the last straw was when her condition went from bad to worse and doctors had to amputate both her legs to save her life. Currently, she is under the care of a leprosy hospital and being helped to cope with her condition both psychologically and medically. Looking at this young lady, I realise my own outcomes could have been so different. I feel maybe if she had access to opportunities to learn about self-care, and community care, her limbs could have been saved.

Self-care is very important for individuals who are likely to have long term impacts of leprosy, including ulceration. For those living in communities of people affected by leprosy, setting up groups where people going through the same experiences and facing the same challenges can share their experiences can really make a difference. Leprosy can leave many people with dry skin, sores, etc. Such conditions need special care including soaking, massage and, if the condition includes ulceration, then applying clean bandages also becomes critical. Having support and encouragement from others can help maintain a self-care routine.

Our quest must be to make sure that every person who has had leprosy does not have to live the rest of their lives burdened by the negative consequences. Self-care can definitely help people affected by leprosy to stay safe.

\section{Discussion}

In a companion article in this series, we describe the systems and organisation level conditions necessary for promotion of effective and acceptable self-care on three levels - level 1: the organising authority (macro-level); level 2: facilitations (meso-level); level 3: the community (micro-level). Within the micro-level are the community leaders and individuals performing self-care. Self-care by people affected by leprosy may be practised in any setting - home, community, primary care or even in secondary care. Often, people may be treated as an in-patient for a complicated ulcer and remain in a self-care unit while ulcers heal, like in Anandaban hospital in Nepal.

The practices of self-care of the four people described above provide different views of how they received their initial diagnosis and how they have managed to continue with their dayto-day lives, incorporating self-care. Hospitals, as well the community of people and patients within the hospital setting, play a vital role in the lives of these patients and are a place where it seems a lot of teaching and learning of self-care takes place. It is therefore important to have multiple levels and organisations engaged when planning and implementing self-care programmes for people affected by leprosy.

\section{Ethics approval}

Not required.

\section{Competing interests}

The author has no competing interests. 


\section{Funding}

SC is funded by the National Institute for Health Research (NIHR: 200132) using UK Aid from the UK Government to support global health research.

\section{Acknowledgements}

I acknowledge the contribution of members of the NIHR RIGHT grant team including Jo Sartori, senior programme manager, and Richard Lilford, Director of the NIHR RIGHT funded project at University of Birmingham. I would also like to acknowledge Magdalena Skrybant for her continued support in engaging with patient and public representatives and bringing forward their views so that their voices are heard; and Joydeepa Darlong (The Leprosy Mission Trust, India) and Indra Napit (The Leprosy Mission Nepal) for their help in establishing links with persons with leprosy to provide their views of self-care. I also acknowledge and thank the four contributors who have kindly shared their account of practising self-care.

\section{References}

1 Watson JM. Essential Action to Minimise Disability in Leprosy Patients. London: Leprosy Mission, 1986. 